\title{
Evaluation of Community Perspectives on National Health Insurance Policy to Health Service Delivery in Ghana
}

\author{
Dr. Da Costa Aboagye \\ Lecturer- Health Promotion and Public Health \\ College of Nursing, Midwifery and Healthcare \\ University of West London \\ Paragon House, Boston Manor Road \\ Brentford, Middlesex TW8 9GA, UK \\ Email: Da-Costa.Aboagye@uwl.ac.uk \\ Professor Jane South \\ Professor of Healthy Communities \\ Leeds Beckett University \\ School of Community Studies \\ Civic Quarter, Leeds LS1 3HE, UK \\ Email: J.South@leedsbeckett.ac.uk \\ Professor Hafiz T.A. Khan \\ Professor of Public Health \\ The Graduate School \& College of Nursing, \\ Midwifery and Healthcare \\ University of West London \\ St Mary's Road, Ealing \\ London W5 5RF, UK \\ Email: hafiz.khan@uwl.ac.uk
}

\begin{abstract}
The paper aims to examine National Health Insurance Scheme (NHIS) policy from the perspective of local communities. Qualitative data from nine key informant interviews and seventy-two community respondents in nine focus group discussions (FGD) were conducted. The FGDs took place in seven different communities in seven regions of Ghana. The data were analysed using thematic network approach. The findings noted a disconnection between NHIS policy and community life. More so, the findings showed an explicit link between equity and access with its impacts on health outcomes. The qualitative results indicated lack of voice and understanding as features limiting people from accessing the NHIS facilities. Understanding of equity as a key theme revealed: first, lack of stakeholder engagement and consultation or
\end{abstract}


participation in the NHIS decision making process. Second it was established that while the policy indicated a will to include all the core poor for an equitable NHIS, there is lack of willingness to implement this aim fully. Finally, despite being a pro- poor intervention by name, practical management of the NHIS is transmitted down vertical silos from the national level, with the lack of joined-up government at the centre undermining local partnerships. Thus, not only are national expectations being dashed locally, local expectations are dashed nationally. The paper proposes that community viewpoints should be given higher priority given that NHIS has since its inception been associated with medical treatments and biomedical paradigm. Promoting community participation, understanding and voices should be recognised to shape the future NHIS policy and practice.

\section{Introduction}

The National Health Insurance Scheme (NHIS) in Ghana is a type of national health insurance established by the Government of Ghana, with a goal to provide equitable access and financial coverage for basic health care services to Ghanaians (National Health Insurance Scheme (2004).The NHIS policy introduced in 2003 is part of a national framework in Ghana aiming to curtail out of pocket (OOP) payment at the point of care and to guarantee fairness of access, chiefly for poor people (National Health Insurance Scheme 2003: 2004). The NHIS is backed by legislation that excludes some members of society (younger than 18 years and older than 69 years) from paying insurance premiums. It also promises premium exemption for the core poor (National Health Insurance Scheme Act 2003).

In 2012, a new NHIS Act 852 was developed with the view to curtail OOP payments and to build on the successes of previous NHIS Act of 2003 (NHIS Act 852: Witter et al., 2013). Out of pocket expenditure still dominate the NHIS more ten years since its inception (Oxfam, 2013) and only $34 \%$ of the population is covered (Mensah, 2013). OOP expenditure is also a key concern in many developed countries, see for example, Yusuf and Leeder (2013). Health sector reports in Ghana frequently emphasise the need for dynamic efforts to identify and recruit the poor and to productively actualize pro-poor health financing policies (Akazili et al., 2014; Ghana Statistical Service - GSS, 2014).

As yet, little has been achieved in terms of covering all Ghanaians, irrespective of the social or economic position of households (Oxfam, 2013). Again, the determinants of health and 
methods of addressing fairness in health remain weak (Oxfam, 2013). Various reports outline global policies to identify the impoverished. For example, some of these reports identify impoverished individuals or households through income-related principles such as education, housing characteristics and asset ownership (Apoya and Marriott, 2011; Barimah and Mensah, 2013; Aryeetey et al., 2012). This kind of identification is referred to as proxy means testing (PMT). Another system; so-called geographic targeting (GT), classifies areas or domains into impoverished groups based on cumulative indicators of poverty (Elbers et al., 2007). Participatory wealth ranking (PWR) evaluates poor individuals or households based on the prescribed model of the society in FGDs (Yates et al., 2006; Yates, 2009; Hargreaves et al., 2007). Means testing involves the process of identifying poor households or individuals on the basis of an income or expenditure threshold (Lindert, 2005; Aryeetey et al., 2012; Van Parijs, 2013).

Selection of a policy to adopt in Ghana that will identify and exempt poor people from catastrophic payments is a challenge in the light of the literature available (Jehu-Appiah et al., 2010; Akazili et al., 2014). The fundamental question is which policy identifies all impoverished individuals precisely (maximizing fairness) at the lowest cost (maximizing efficiency). Healthcare systems are not only about promoting health but also about shielding households from financial consequences (Wagstaff, 2010; Aryeetey et al., 2012). Even though a number of studies have examined the implementation of NHIS (Nguyen et al., 2011), its equity significance in relation to community perspective has not been assessed nationally. Thus, the aim of the paper is to investigate the impact of the National Health Insurance Policy from the perspective of local communities in key informant's interviews and FGDs.

\section{Methodology}

Given the exploratory nature of the research, a qualitative approach was adopted. Using this approach allowed the subjective reality of Ghanaians to be captured through people's own individual experiences. This offered the opportunity to gather full and descriptive data concerning individual context. Face to face in-depth interviews of key informants and FGDs of local communities were conducted during the period (August 2015 to August 2016). While the purpose of the focus groups was to assist with community involvement: key informants served as gatekeepers. 
We deliberately selected seven differing communities from seven regions in Ghana for FGDs. The seven selected communities were justified because they were based on their unique geographic characteristics, portraying characteristics of the rural area of Ghana and represent a vast majority of population in the areas of Ghana. Two communities (West Legon in Greater Accra and Buokrom in Kumasi (are well developed and affluent communities with rich people living in the area. Two communities (Abutia (HO) in Volta region and Kwahu-Tafo in Eastern Region) originally small farming villages are both slightly undeveloped and developed and are popularly known as middle-class areas. The remaining three communities (Tolon in Northern Region Ajumako in Central Region, and Bongo in the upper East Region on the other hand, are populated and underdeveloped communities. They are deprived and marginalized communities with serious socio-economic problems.

Local authorities (chiefs, assemblymen, opinion leaders) of these communities were approached so that we could introduce ourselves, and explain the purpose of the study. The authorities of the areas were also informed about the project and the recruitment of participants. When permission was given to recruit from households for the focus groups, invitation letters were distributed to various households from urban to rural communities. For each selected community, on approaching the first house, a coin was tossed. A head meant this house was taken as the first in the counting process, and then the fifth house was selected for inclusion. A tail meant that the second house was considered as number one in the counting process. The fifth house from this was then selected for inclusion. Therefore, every fifth house was selected with the view of inclusion and this continued until one hundred people had been recruited. Information about the nature, purpose and objectives of the study were provided to the invitees in the selected households and their verbal/signature consent was obtained during the FGD.

Lastly, we foresaw the elder- youth socio-cultural relationship, sanctity of authority and traditional respect for elderly, fathers and mothers and so we did a proper pre-orientation for all the respondents; to encourage everyone to contribute. It should also be noted that only people aged 18 years of age and over participated in FGDs. In Ghana, people above aged 18 years and above are classified as adults and they are of voting age. This means that such people do not need the consent from their parents to participate in a research project. They can decide on their own whether to participate or not as it was in the case of this research. 
Twelve key and elite informants were invited but only nine were available at the time of the field work. This is due to the busy schedules of such individuals. We do not know the reasons for non-participation of three individuals, because they did not respond to interview requests. Thus, none of the key informants directly refused to participate. Nine key informant interviews enabled the gathering of information from policy makers, officials from the NHIS and government, Ghana Health Service, Ministry of Health and service providers on the impact of the NHIS policy on the wider community.

A semi-structured interview guide that varied slightly depending on the category of stakeholder was used (that is FGDs and Key Interviews). Interviews were held in either homes or offices and no one was coerced to participate. All participants were promised confidentiality and anonymity, and everyone provided oral/ written consent. Approval to conduct this study was given by the Ghana Health Service and the Ethics committee of Leeds Beckett University respectively.

\section{Data Analysis Approach}

A tape recorder was used to document both the key informant interviews and the FGDs. The tape recording approach allowed us to engage freely in the conversation without worrying about note-taking. The recorded information helped when we were transcribing the data. Brief notes were also taken during the interview, written down and organized at the end of the interview. These notes were used to fill in information gaps as well as to supplement the recorded conversation. It was necessary to get informed consent from the key informant and the focus group participants to audiotape the interview/ focus groups discussions.

The audio taping was discussed with all the participants before scheduling the interview appointments. During interview of one of the key informant, the respondent preferred not to be recorded for fear of such a sensitive tape leaking to the media or to a political opponent. Shorthand notes were taken to gather the information. Thematic analysis is associated with social constructionism and depends on textual data created aside of its advantage of how meanings are constructed (Tuckett, 2005). Attride- Stirling approach uses a thematic network that is outlined as a methodical way of classifying a thematic analysis of qualitative information (Attride- Stirling, 2001). Attride-Stirling (2001) discussed that thematic network innovation enhances the significant elements of qualitative information exploration; such as indexing, 
classifying and coding. Thematic networks are a way of methodically organising initial codes into basic themes and then into organising themes and predominant global themes that briefly summarise features of the data. The Attride-Stirling approach has been chosen for this study because of its systematic way of organising thematic exploration of qualitative data. The key informants' interviews and focus groups were analysed together. This is justified because both key informants' interviews and focus groups produced qualitative data. Again, the respondents of the focus groups and key informant interviews belong to the same socio-cultural Ghanaian environment and, as part of the policy formation process, policy makers normally engage with the beneficiaries of the policy.

\section{Validity}

To achieve rigour, first, this research accepts and uses the social constructionism stance of Denzin, and Lincoln (2005) which is contained in modern qualitative research, with multiple perspectives. This research, adopting the position of social constructionism, enabled a greater understanding of NHIS and allowed multiple perspectives and viewpoints of Ghanaians to emerge. Lastly, to achieve rigour, we applied the principles of transferability. Transferability represents the extent to which the findings of research are valid or applicable to a general population exterior to the research framework (Seale, 2002). Our findings were compared with wider literature and findings from Ghana.

\section{Findings and Discussions}

The findings show a disconnection between NHIS policy and community life in Ghana. First, the qualitative results noted lack of voice and lack of understanding as features limiting people from accessing the NHIS facilities. Figure 1 denotes the focus groups and key informants sample characteristics.

\section{Lack of voice and understanding}

The focus group participants demonstrated a lack of understanding both of the insurance scheme rationale and of the procedures for registration; as well as the procedure to register as a core poor. Their non-membership clearly had a significant relationship with their understanding of insurance concepts. Understanding of insurance can aid adverse selection. 
According to the Focus group respondents, people will prefer to register when vulnerability is high. Focus group 3 (participant 3I): "I have registered for my sick mum but I haven't registered myself because I am fit". This means risk aversion and the need to make gains from insurance influence membership. The perception of being healthy and the lack of understanding of insurance may decrease memberships. Focus group 9 (participant 9D): "I am healthy so why should I register and pay healthcare cost when I actually do not need it".

This statement discloses that feeling healthy may mean that healthy individuals feel no need to enrol. It is important to explain the concepts of NHIS membership to people with less vulnerability. Membership of the NHIS will increase if healthy individuals understand the principles of insurance. It can also help to build solidarity in that the more the healthy groups are contributing to healthcare, is the more resources will be available to support the less vulnerable in society.

\section{Understanding of NHIS Principles and Solidarity through Community Engagement}

Focus group participants have a lack of understanding of the insurance scheme and their nonmembership was clearly related to their understanding of the concept of insurance.

Focus group 4 (Participant 4E) said:

"I'm not ill so I don't need insurance"

Tones and Green (2010) note that, given appropriate information and opportunity, individuals will choose activities and behaviours that enhance their health. Sharing knowledge about the benefits of NHIS membership will promote solidarity, increase involvement and therefore impact on NHIS membership.

According to $\mathrm{Xu}$ et al (2005) solidarity is a concept of health insurance that can increase membership of NHIS since it creates social cohesion.

The self- evaluation of individual wellbeing affects the choice to use NHIS as demonstrated by (participant 5B) in Focus group 5: Focus group 5 (participant 5B):

Focus group leader - "Are any of you part of the insurance?" Answer - "No, I am not sick so why should I join the scheme”. 
Jacobs and Goddard (2000) showed that greater solidarity in a community insurance scheme can help individual members willing to support one another to manage risk. Community members, when helped to understand the solidarity rationale, may support such a value or philosophy to enhance membership since NHIS does not operate on mutual benefit (Diaz and Echevarria, 2002). Komter (2001) argued that building solidarity via community participation can build up a sense of cohesion and this can serve as a good foundation for the institution of a formal NHIS. If the NHIS engage community members through local stakeholder consultations rather than elite groups, it can promote understanding of the scheme to build social cohesion and increase membership. By promoting the understanding and acceptance of the NHIS foundation, individual members will be willing to support one another to manage risk.

\section{Empowerment}

Second, the qualitative results revealed lack of stakeholder engagement and a lack of consultation or participation in the NHIS decision making process.

According to key informant E: "The NHIS should do more to empower local people as well as frontline staff to bring about improvement in local health services and also enhanced skills of staff."

Some of the focus group participants also felt disempowered. Focus group 6 (participant 6B) argued that: "I do not have sufficient information about the NHIS and not even my rights". According to Equality and Human Rights Commission (2011), the right to health is also the right to participate in all health-related decision-making at community, national and international levels. In order to participate properly, people also need to enjoy the right to receive and impart information.

Focus group 8 (participant 8D) "It is sad the community was disempowered by exclusion from the NHIS decisions". South et al (2005) noted that effective partnership between leaders and communities can create robust partnerships that improve participation, empowerment and counteract the process of disempowerment. According to Nutbeam (2000), raising education and awareness on citizens' rights and responsibilities can facilitate participation and empowerment. Sen (2009) notes, participation and empowerment are not merely a means to an end. Involvements of people in the NHIS activities and decisions provide an opportunity for people (especially those who are affected by the NHIS decisions and processes) to be active 
agents of their own density; thus, it is fundamentally important to reclaiming dignity. This means empowerment of persons (the vulnerable and poor people affected by the NHIS) to be active in the NHIS decisions and processes, should be a means of realizing their rights and an end in itself. The LEAP project has the prospect over time to become a significant participatory structure, it can be noted that throughout this period of NHIS reform since 2003 and restructuring, NHIS has not developed mechanisms and activities to engage with local communities. Tasks such as ensuring the representation of different interests and handling contested decisions have been indirectly delegated to decision-makers and executives. Regrettably, the very leaders who give emphasis to devolution, community empowerment and people centred approaches are those who tend to declare a new national programme or standard every time they make a major speech.

Focus group 5 (participant 5B): "What did the government not promise in their election speeches about NHIS programme". After speeches and grandstand statements, there is not much left for the poor and lay people to decide. Obviously, one programme contradicts or impairs another. Focus group 5 (participant 5B): “They promise one time NHIS premium programme ... now. They are doing another programme of NHIS capitation...I have lost confidence in their capacity to give use one time NHIS premium." Under the National Democratic Congress government, a repeated emphasis on listening to the voices of poor/lay people and communities has not been matched by a visible shift towards policies that aim to tackle NHIS inequalities and social exclusion through processes of community participation and partnership working. For example, the NHIS depicted a tradition of community participation in health and this underscored the significance of communities and individuals taking more responsibility for health, and valuing lay voices, experiences and skills. Despite this finding, the funding of the NHIS has been centralised. The NHIS policy, 2012 (Act 852) centralises the funds of the scheme (NHIS policy 2012). Commitment to change and the need to be clear about the levels and extent of participation is the way forward for the success of NHIS. Matters surrounding representation, devolution and a people centred approach also need to be addressed. Key Informant A: "Centralisation of the funding of the NHIS is very bad for our decentralisation ambition as a country. It means the government is taking power from the people." 


\section{Lack of Participation in the NHIS Decision Making Process.}

The evidence from the Focus group discussions is similar to the revelations of the key informant on the lack of participation in the NHIS decision making process. Key informant I: "As the chief executive of the community I did not participate in the decision-making process to impose the capitation pilot of the NHIS on this community. I have received many complaints from the community. At least they should have contacted the community”.

Participants were dissatisfied with the fact that they were not involved in the NHIS decision making process. The managers had imposed the NHIS capitation and this had had a bad impact on their health and community. Focus group 5 (participant $5 \mathrm{H}$ ): "I went to the hospital today with my insurance card, but they charged me because they say the money paid by government is too small to cover all my hospital bills". The Focus group participants felt disappointed, excluded and marginalized in the decision-making process to impose the capitation on them. Focus group 7 (participant 7B) had this to say: "I'm very disappointed that when I'm sick I can't go to the hospital because I don't have the means. No one cares about my welfare because I'm poor. My friend told me that they have increased the insurance, but I don't have lorry fare to go and check. I feel so disappointed that they did not tell us before the increase". Some Key Informants accused the NHIA of taking decisions without consultation or taking decisions from the centre. These Key Informants argued that abiding by the drug list would not warrant clients the highest quality of healthcare. Key Informant G: "We the medical specialists prescribe medication, yet we have little influence over the decisions on the drug prescription list". According to the Key Informants, decisions on prescription forms, assessment of claims and payments must involve the service providers for an efficient service. This suggests that decisions taken at the local level are more likely to succeed within the community than those taken by central management; since this approach builds inclusion and cohesion.

It was established that while the policy indicated a will to include all the core poor patients for an equitable NHIS, there is lack of willingness to implement this aim fully. The study also explored the understanding of Key Informants of the equity aims of the NHIS policy. It was established that the will to include all the core poor patients for an equitable NHIS is good on paper but practically it seems there is a lack of willingness to do this on the part of the management of the NHIS. Some of the Key Informants suggested that: "The problem is not with the policy aims but the resources to include all the core poor. It is expensive" -Key 
Informant H. Some of the Key Informants also queried the realistic nature of the policy aim and whether any milestones are set to achieve it. Key informant G: "If the government is serious to reduce inequities within the NHIS policy, they would have given timelines and set the objectives clear. The objectives of equity cannot be achieved without milestones". Others complained about the strict selection criteria used for classification as core poor. Some of the Key Informants note how the government can identify the poor for NHIS exemptions with this strict LI 1809. Key informant E: "Let us be truthful, it is just on paper to exempt the poor but there is no political will or interest to do so" The poverty of the poor was stated by some Key Informants to be seasonal and temporary. Key informant F: "The government should stop this indigent thing. If the government is to give free care to all that is fine, so that everyone can benefit. What is equity about paying for your health? The lack of money for the farmers to pay for the NHIS is temporary. They can save money to pay for future NHIS.

\section{Shifting the Balance of Power to Local Communities}

According to informants and Focus group participants, stakeholder engagements in the NHIS is by political decision; with no or little consultation of lay people, NGOs, civil society groups and service providers. In fact, all the findings of FGDs and some Key Informants show no community discussion of the NHIS policy in the selected community before the introduction of the policy as demonstrated by some of the FGDs. Interviewer: "Were you involved/consulted in the development of the NHIS policy?" Key informant B answered: "No. We were not consulted and even this capitation that is being piloted was just imposed on us. Look at my position but I was only informed via email after everything has been done in head office in Accra”. Some Focus group participants shared the same sentiments. Focus group 7 (participant 7G) quoted that: "We were not consulted/involved before the introduction of the NHIS policy". The NHIS can have a leading role in building relationships with local communities. While community participation is a nice expression and one that needs backing in the 21 st Century, the greatest task is shifting from rhetoric to reality. This would require leaders and people in NHIS and healthcare to be willing to work in diverse ways to support community actions and develop local partnerships.

Shifting the balance of power should entail that community participation no longer be on the marginal but must be part of the standard way of doing NHIS business (Springett, 2001). This will bring about a social reform that aims to adjust not only what takes place but the way it occurs in NHIS decision making process. According to Springett and Young (2002) methods 
like social entrepreneurship can help the NHIS consult better with local communities. The findings revealed little community engagement and bureaucratic system as demonstrated by some participants as: "Registration to be a member of NHIS involves a lot of paper work, long processes, rules and procedures. I have to travel four times to chase my NHIS Card in their office”- Focus group 3 (participant 3E).

But where NHIS conventional services are bureaucratic, administrative and slow to change, social capitalists or entrepreneurs are inventive. South, et al, (2008) posit that social entrepreneurship is not only about bringing qualities associated with the profit-making sector into NHIS services but also entails working with communities, policy makers (and other stakeholders) in a robust way by building networks and systems and finding local solutions. As noted by some Key Informants that the "NHIS should work with local communities because that is the only way the scheme can succeed not centralisation” - Key Informant E.

Social entrepreneurship involves working with local communities and encourages social capital in communities; so that local individuals could be assisted as social entrepreneurs (South et al, 2010). Alborz et al. (2002) argue that social entrepreneurship is not a set of designs, but it is more a way of working and the readiness to develop the prospects or opportunities for dealing with social change. For NHIS policy makers or executives associated with execution of NHIS policy, the theory of social entrepreneurship might seem too disjointed and it can be problematic to imagine what it would look like in the field or on the ground. The question is what social entrepreneurship can offer the NHIS.

South et al. (2010) argue that social entrepreneurship is a way of working that is centred on finding new and flexible solutions to social challenges and bringing about change. Some Key Informants also complained about the scarcity of resources for the NHIS to identify all the poor individuals. But social entrepreneurs, as individuals or groups, use existing skills and resources amenably and creatively (South et al, 2008)). Social entrepreneurship can provide a way of joining up the NHIS with local communities. The NHIS policy can also target aiming around community engagement; through a flexible and capacity building approach, especially for poor individuals and groups. Taking advantage of small opportunities may certainly advance work further in the community and help the NHIS connect with marginised and disadvantaged poor people. Striving to work, make, support and strengthen realistic or real-life networks should not substitute for community participatory structures. However, these efforts should be used to 
improve access and information flow between NHIS and community sectors. Since social entrepreneurship is based on the use of existing opportunities and resources, it can make community participation more obvious and achievable for both NHIS and the people working in the community. Very little or small successes by the NHIS can build trust and credibility. Cumbersome processes and hierarchical organizations can slow effective community participation. Social entrepreneurship, though not a general panacea, can avoid some of the barriers and make the most of the existing opportunities. Of course, social entrepreneurship is not a method without risk. It requires high-level responsibility to support people prepared to work in this way. It also calls for institutes and services to be outward looking, to search for innovative opportunities whilst nurturing mutual respect for the skills and resources to be created in any community.

\section{Engaging and Supporting the More Marginalized/Poor Groups}

Ghana's NHIS though has a policy to cover the poor; in practice has fallen short of its objective based on the evidence presented by Key Informants and FGDs. The NHIS policy effort should not only be focused on health improvement but must involve addressing health inequalities and promoting equity. Working to engage and to support the more marginalized and poor groups in society throw up major challenges for NHIS policy in practice. This was emphasised by some informants interviewed: "The problem is how to identify the hard to reach poor/marginalised groups for exemption and I hope your research can help" - Key Informant D.

Jehu-Appiah et al. (Aryeetey et al., 2012) identify that targeting of the poor based on income levels is inefficient because income levels of self-employed people in the informal sectors are difficult to determine. There are also groups who qualify as indigents, but these people are marginalised and hard to reach. Some people may not be aware of the procedures for obtaining NHIS benefits. The second task relates to the conduct of NHIS policy implementation in reallife situations. Probably, this is where the NHIS has been exposed in its objective to dealing with equity, as some Key Informants note that NHIS has failed to identify the poor for exemption in practice. Where proper strategies are not put in place to identify all the poor/marginalised groups for exemptions, the risk is that the NHIS policy will result in some voices being ignored. It is precarious that NHIS policy does not weaken the policy implementation, practice and make worse inequalities. Despite being a pro- poor intervention by name, practical management of the NHIS as found is transmitted down vertical silos from 
the national level, with the lack of joined-up government at the centre undermining local partnerships. Thus, not only are national expectations being dashed locally, local expectations are dashed nationally (Exworthy, 2002; 2003).

\section{Conclusions}

The NHIS responses to the poor and community participation agenda need to incorporate an attempt to win over "hearts and minds" as well as implementation of operational changes; the two characteristics are connected. The Focus groups and Key Informants established lack of participants and lack of planning for advancing community participation in the NHIS and uncertainty about how to involve poor people and communities. Involving poor people and encouraging community participation requires new skills and many groups of NHIS professionals lack experience of dealing with community groups and members of the community in the context of the NHIS participatory processes. In conclusion, community viewpoints should be given higher priority given that NHIS has since its inception been associated with medical treatments and biomedical paradigm. Promoting community participation, community understanding, and community voices should be recognised to shape the future NHIS policy and practice.

\section{REFERENCES}

Alborz, A., Wilkin, D., and Smith, K. (2002). Are primary care groups and trusts consulting local communities? Health and Social Care in the Community 10(1):20-27.

Akazili, J., Welaga, P., Bawah, A., et al. ( 2014). Is Ghana's pro-poor health insurance scheme really for the poor? Evidence from Northern Ghana. BMC Health Services Research14:637.

Apoya, P. and Marriott, A. (2011). Achieving a shared goal: Free universal health care in Ghana. Oxford: Oxfam International. 
Attride-Stirling, J. (2001). Thematic networks: an analytic tool for qualitative research. Qualitative Research 1(3):385-405.

Aryeetey, GC., Jehu-Appiah, C., Spaan, E., Agyepong, I., and Baltussen, R. ( 2012). Costs, equity, efficiency and feasibility of identifying the poor in Ghana's National Health Insurance Scheme: empirical analysis of various strategies. Tropical Medicine \& International Health $17: 43-51$.

Barimah, K. and Mensah, J. (2013). Ghana's National Health Insurance Scheme: insights from members, administrators and health care providers. Journal of Health Care for the Poor Underserved 24:1378-90.

Denzin, N. and Lincoln, Y. (2005). Introduction: the discipline and practice of qualitative research. In Denzin, N. and Lincoln, Y. (Eds.), Handbook of Qualitative Research (pp. 1-17). Thousand Oaks, CA: Sage.

Diaz, A., and Echevarria, C. (2002). Solidarity, Transfers, and Poverty. Review of Development Economics 6(3):337-350.

Elbers, C., Fuji, T., Lanjouw, P., Ozler, B. and Yin, W. (2007). Poverty alleviation through geographic targeting: how much does disaggregation help? Journal of Development Economics 83:198-213.

Equality and Human Rights Commission (2011). The Public Sector Equality Duty. Judicial Review 16(1):1-13.

Exworthy, M., Berney, L. and Powell, M. (2002). "How Great Expectations in Westminster May Be Dashed Locally": The Local Implementation of National Policy on Health Inequalities. Policy and Politics 30(1):79-96.

Exworthy, M., Blane, D. and Marmot, M. (2003). Tackling Health Inequalities in the UK: The Progress and Pitfalls of Policy. Health Services Research (part 2) 36(6):1905-21. 
Ghana Statistical Service (GSS) (2014). Ghana Living Standards Survey. Report of the sixth Round (GLSS 6). Accra, Ghana.

Hargreaves, J., Morison, AL, Gear, JSS. et al. (2007). Assessing household wealth in health studies in developing countries: a comparison of participatory wealth ranking and survey Burkina Faso: a community-based targeting approach to exempt the indigent from user fees. BMC Public Health 10:631.

Jacobs, R. and Goddard, M. (2002). Trade-offs in social health insurance systems. International Journal of Social Economics 29(11):861-75.

Jehu-Appiah, C., Aryeetey, G., Spaan, E., Agyepong, I. and Baltussen, R. (2010). Equity, efficiency and feasibility of strategies to identify the poor: an application to premium exemptions in Ghana's National Health Insurance. Health Policy 95:166-173.

Jehu-Appiah, C., Aryeeteya, G., Spaana, E., de Hoop, T., Agyepong, I., Baltussena, R. (2011). Equity aspects of the National Health Insurance Scheme in Ghana: Who is enrolling, who is not and why? Social Science and Medicine 72(2):157-165.

Komter A.E. (2001). The disguised rationality of solidarity: gift giving in informal relations. Journal of Mathematical Sociology 25:385-401.

Lindert, K. (2005). Implementing Means-Tested Welfare Systems in the United States. Social Protection Discussion Paper Series No. 532. World Bank, Washington, DC.

Mensah, S. (2013). Ghana revises figures on NHIS coverage Joy News 4/3/2013 [internet] http://edition.myjoyonline.com/pages/news/201303/102239.phpDate accessed 3/4/2013

Nutbeam, D. (2000). Health literacy as a public health goal: a challenge for contemporary health education and communication strategies into the $21^{\text {st }}$ century. Health promotion international 15(3):259-267.

National Health Insurance Scheme (2004) Regulation (LI 1809) Accra: Ghana Publishing Company Limited. 
National Health Insurance Scheme Act (2003) Act of Parliament in 2003 (Act 650) Ghana.

National Health Insurance Policy (2012) Act, 852 Accra: Ghana Publishing Company Limited.

Nguyen, H.TH., Rajkotia, Y. and Wang, H. (2011). "The Financial Protection Effect of Ghana Health Insurance Scheme: Evidence from a Study in Two Rural Districts." International Journal for Equity in Health 10(4):1-12.

Oxfam (2013). Universal health coverage: why health insurance schemes are living the poor behind. Oxfam International, briefing paper, October.

Seale, C. (2002). Quality issues in qualitative inquiry. Qualitative Social Work 1(1):97-110.

Sen, A. (2009). The idea of justice. London: Allen Lane/Penguin.

Springett, J. (2001) 'Participatory Approaches to Evaluation in Health Promotion', in I. Rootman, M. Goodstadt, B. Hyndman, et al. (eds) Evaluation in Health Promotion: Principles and Perspectives, pp. 83-105. Copenhagen: World Health Organization.

Springett, J., and Young, A. (2002). Evaluating community-level projects: comparing theories of change and participatory approaches, In I- Bauld and K. Judge (eds) Learning front Health Action Zones. Chichester. Aeneas Press.

South, J., Darby, F., Bagnall, A.M. and White, A., (2010) Implementing a community-based self-care training initiative: a process evaluation. Health \& social care in the community, 18(6), pp.662-670.

South, J., Higgins, T.J., Woodall, J. and White, S.M. (2008). Can social prescribing provide the missing link? Primary Health Care Research \& Development 9(4):310-318. 
South, J., Fairfax, P. and Green. E. (2005). Developing an assessment tool for evaluating community Involvement. Health Expectation 8:64-73.

Tones, T. and Green, J. (2010). Health Promotion: Planning and Strategies, 2nd ed., Sage, London.

Tuckett, A.G. (2005) Applying thematic analysis theory to practice: a researcher's experience. Contemporary Nurse 19(1-2):75-87.

Van Parijs, P. (2013). Rethinking poverty in the developed world, 5th European Public Policy Conference [internet] $\underline{\text { http://eppc2013.wordpress.com/2013/04/19/philippe-van-parijs-the- }}$ euro-dividend/Date accessed 6/9/16.

Wagstaff, A. (2010). Estimating health insurance under unobserved heterogeneity: The case of Vietnams Health Care Fund for the poor. Health Economics19:189-208.

Witter, S., Garshong, B., Ridde, V. (2013). An exploratory study of the policy process and early implementation of the free NHIS coverage for pregnant women in Ghana. International Journal for Equity in Health 12(16):1-11.

Yates, J., Cooper, R. and Holland, J. (2006). Social protection and health: experiences in Uganda. Development Policy Review 24:339-356.

Yates, R. (2009). 'Universal health care and the removal of user fees', The Lancet 373(9680):2078-2081

Yusuf, F. and Leeder, S.R. (2013). "Can't escape it: the out-of-pocket cost of health care in Australia", The Medical Journal of Australia 199(7):475-478.

Xu, H., Carrin, G., Muchiri, S. (2005). An empirical model of access to health care, health care expenditure and impoverishment in Kenya: learning from past reforms and lessons for the future. Geneva: World Health Organization. 


\section{Biography:}

Dr Da Costa Aboagye is a research and academic practitioner at the University of West London in the United Kingdom. He specialises in Health Promotion (Health and Wellbeing) and Public Health with special interests in National/Social Health Insurance Schemes Finance, Universal Health Coverage, Global Health, Health Impacts Assessment, Sustainable Development, Equity, Human Rights, Social Determinants, Social Protection, Politics, Poverty, Community and Healthcare. He is the lead for the Ghana Government project of establishing a Health Promotion Division in Ghana to champion the Health Promotion needs of Ghana and globally. "Implementation plan for health promotion division in Ghana"- Working paper submitted $4^{\text {th }}$ December 2017 - Dr Da Costa Aboagye

Professor Jane South is Professor of Healthy Communities working in the field of volunteering, active citizenship and community health. Jane has a national and international reputation for her research on lay health workers and volunteer roles in health. She has a long standing interest in community engagement and is currently on secondment to Public Health England as an expert advisor on community-centred approaches for health and wellbeing. From 2006-2013, Jane was Director of the Centre for Health Promotion Research at our University where she built up an extensive portfolio of research, publications and public engagement activity.

Professor Hafiz T.A. Khan is Professor of Public Health at University of West London in the UK. He is also an associate research fellow at the Oxford Institute of Population Ageing, University of Oxford, UK. He trained as health statistician and developed his academic career in the area of public health over the last 25 years. His current research interests include healthy ageing, co-morbidity in later life, long-term care and support provisions for elderly. He has published important articles in health and population related issues. He has co-authored two books "Research Methods for Business and Social Science", Sage, 2007 \& 2014. 
Figure 1 - Sample survey

\section{Total number of Respondents $(\mathrm{n})=81$}

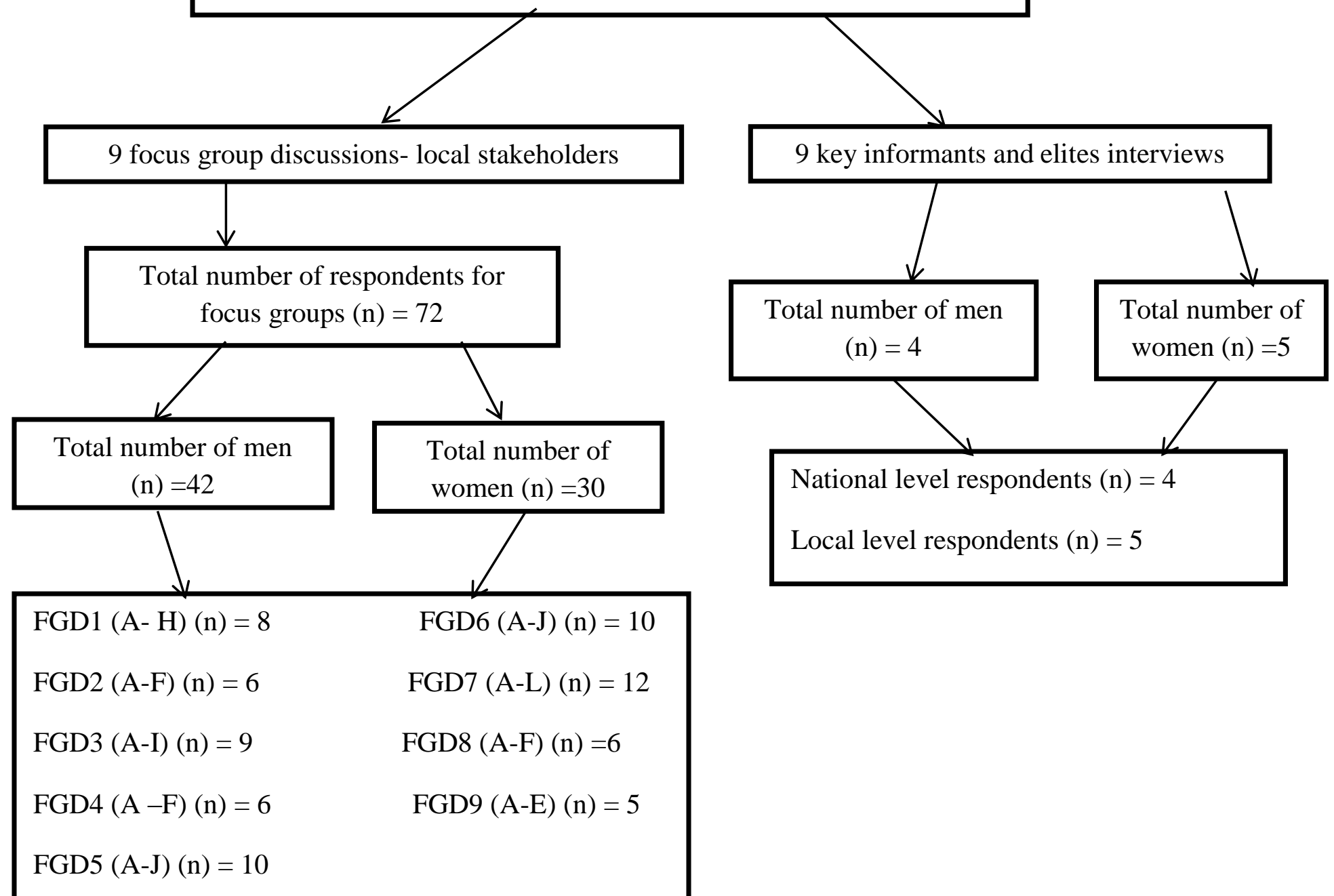

